\title{
Crescimento de mudas de Dipteryx alata sob adubação fosfatada e calagem
}

Seedling growth of Dipteryx alata under phosphorus fertilization and liming

\author{
Eliane Cristina Sampaio de Freitas $\left.{ }^{1}{ }^{*}\right)$ \\ Haroldo Nogueira de Paiva ${ }^{2}$ \\ Helio Garcia Leite ${ }^{3}$ \\ Sílvio Nolasco de Oliveira Neto ${ }^{4}$
}

\section{Resumo}

Dipteryx alata, espécie do Cerrado, se destaca pelo potencial, na agroindústria e recuperação de áreas degradadas. Este estudo objetivou avaliar o crescimento de suas mudas em função da adubação fosfatada $(\mathrm{P})$ e da saturação por bases do substrato $(\mathrm{V})$. Os tratamentos foram representados por um fatorial de sete níveis de $\mathrm{P}$ e quatro níveis de $\mathrm{V}$, dispostos no delineamento em blocos casualizados, com cinco repetições. Aos 120 dias após a semeadura, foi medida a altura da parte aérea $(\mathrm{H})$, o diâmetro do coleto (DC), e obtida a massa de matéria seca da parte aérea (MSPA), de raízes (MSRA) e total (MST), e suas relações. Foi observado sistema radicular bem desenvolvido, com relação MSPA/MSRA, igual a 1. A maioria das características apresentou valores máximos em V igual a 20\% e no tratamento sem fósforo. Assim, para as condições estudadas, recomenda-se a elevação de V para 20\% sem necessidade de aplicar fósforo.

Palavras-chave: Produção de mudas; Fósforo; Saturação por bases.

\section{Abstract}

Dipteryx alata, species occurring in the Cerrado Biome, has potential use in agroindustry and recuperation of degraded areas. This study aimed to evaluate the growth of its seedlings in function of phosphorus fertilization $(\mathrm{P})$ and base saturation of the substrate $(V)$. The treatments were arranged in a factorial design with four levels of $V$ and

1 Dra.; Ciência Florestal; Universidade Federal de Viçosa, UFV, Brasil. Rua Riachuelo, 71, Centro; CEP:35790-000 Curvelo, MG - Brasil; E-mail: elianesampaiofreitas@hotmail.com (*) Autor para Correspondências

2 Dr.; Ciência Florestal; Universidade Federal de Viçosa, UFV, Brasil; Professor da UFV, Universidade Federal de Viçosa, Centro de Ciências Agrárias, Departamento de Engenharia Florestal. Avenida Ph Rolfs, s/n. Campus UFV, CEP:36570000 - Vicosa, MG - BrasiL; E-mail: hnpaiva@ufv.br”

3 Dr.; Ciência Florestal; Universidade Federal de Viçosa, UFV, Brasil; Professor da UFV, Universidade Federal de Viçosa, Centro de Ciências Agrárias, Departamento de Engenharia Florestal. Avenida Ph Rolfs, s/n. Campus UFV, CEP:36570000 - Vicosa, MG - BrasiL; E-mail: hgleite@ufv.br

4 Dr.; Ciência Florestal; Universidade Federal de Viçosa, UFV, Brasil; Professor Associado, atuando na Graduação e PósGraduação, e Coordenador do Curso de Engenharia Florestal da Universidade Federal de Viçosa; Universidade Federal de Viçosa, Departamento de Engenharia Florestal. Av. P.H. Rolfs, s.n. Campus Universitário, CEP:36570000 - Viçosa, MG - Brasil.E-mail: snolasco@ufv.br 
$\mathrm{w}$ seven levels of $\mathrm{P}$ in randomized block with five replications. At 120 days after sowing, the height of the aerial part (H), collar diameter (DC), dry matter of shoot (MSPA), root (MSRA) and total (MST) were measured, and its relations were calculated. Seedlings had well developed root system, with MSPA/MSRA equal to 1 . The most of characteristics had maximum values in $V$ equal to $20 \%$ and in the treatment without phosphorus. Thus, for the same conditions studied, it is recommended to increase $V$ to $20 \%$ without application of phosphorus.

Keywords: Seedling production; Phosphorus; Base saturation.

\section{Introdução}

O crescimento populacional e a exploração insustentável dos recursos naturais culminaram na degradação ambiental e aumento do número de espécies ameaçadas de extinção. Entre os biomas brasileiros, o Cerrado é o que sofre as maiores intervenções em termos de aberturas de novas áreas para atividades agropecuárias (SANO et al., 2001), com quase metade da sua área desmatada e cerca de 130 espécies da flora ameaçadas de extinção (IBGE 2012). Entre os principais fatores que ocasionam a redução da biodiversidade do Cerrado destacam-se a degradação ambiental das áreas e a invasão biológica causada por gramíneas exóticas (KLINK \& MACHADO, 2005).

Para a recuperação de áreas com alto nível de degradação e predomínio de invasoras agressivas, o plantio de mudas de espécies arbóreas apresenta maior eficácia no estabelecimento das plantas, proporcionando, com o passar do tempo, o desenvolvimento de espécies de outros níveis de sucessão. Nesse sentido, as espécies frutíferas nativas se destacam no processo de recuperação, uma vez que atraem animais frugívoros dispersores de sementes. Silva et al. (1994) ressaltam que o plantio de frutíferas do Cerrado, além de proporcionar a preservação dessas espécies, apresenta-se como potencial para a agroindústria, uma vez que a maioria dos frutos possuem elevados teores de açúcares, vitaminas e sais minerais. É notório o potencial de comercialização dos frutos dessas espécies, não apenas local, mas internacionalmente, como o licor de pequi que já é exportado para o Japão e a amêndoa de baru para a Alemanha (AVIDOS \& FERREIRA, 2000).

A Dipteryx alata Vogel, popularmente conhecida como baru, é uma espécie secundária, pertencente à família Fabaceae, que ocorre no Cerrado (CARVALHO, 1994) e se destaca pelo potencial alimentício. A polpa do fruto pode ser consumida "in natura" ou na forma de doces e geleias, e a amêndoa pode ser consumida crua, torrada ou processada na forma de doces e paçoca (SILVA et al., 1994). As amêndoas constituem uma fonte significativa de proteínas e fibras, além do alto grau de insaturação do óleo, favorecendo seu uso para fins comestíveis ou como matériaprima para as indústrias farmacêutica e oleoquímica (TAKEMOTO et al., 2001).

Essa espécie também pode ser usada para o paisagismo, fins madeireiros, construção naval e civil (LORENZI, 2002), produção de mourões (SANO et al., 1999), utilização da celulose na confecção de papéis para rápida impressão, de embrulho e embalagens (ANDRADE \& CARVALHO, 1996), e para recuperação de áreas degradadas em solos com boa drenagem (CARVALHO, 1994).

Para o sucesso de projetos de recuperação ambiental, além da escolha de espécies adaptadas às condições edafoclimáticas do local, devem ser utilizadas mudas de boa qualidade, com nutrição e substratos adequados (GONÇALVES et al., 2005), ocasionando a maior sobrevivência e 
crescimento pós-plantio e, consequentemente, redução da necessidade de replantio e frequência de tratos culturais (CARNEIRO, 1995).

A terra de subsolo é um dos substratos mais utilizados nos viveiros para produção de mudas de espécies arbóreas nativas. Entretanto, a maioria dos solos do Brasil possui elevada acidez e baixa disponibilidade de nutrientes, principalmente fósforo, que pode ser responsável pelo menor desenvolvimento das plantas (FURTINI NETO et al., 1999). Essas características, apesar de limitantes ao crescimento, não podem ser consideradas como entrave para utilização desses solos, uma vez que podem ser manejadas e corrigidas. A calagem em solos ácidos é a maneira mais eficiente para aumentar a disponibilidade de fósforo, elevando o $\mathrm{pH}$ e, consequentemente, a densidade de cargas negativas, acarretando maior repulsão entre o fósforo e a superfície adsorvente, reduzindo a capacidade máxima de adsorção de P do solo (NOVAIS \& MELLO, 2007).

Para otimizar a utilização de insumos e produzir mudas de qualidade, é necessário conhecer as exigências nutricionais das espécies, uma vez que essas são variáveis. No entanto, são ainda incipientes as informações disponíveis sobre o comportamento das espécies arbóreas no que diz respeito aos requerimentos nutricionais e a sua capacidade de adaptação a condições ambientais distintas (FURTINI NETO et al., 1999).

Diante do exposto, o presente estudo teve como objetivo avaliar o crescimento de mudas de Dipteryx alata Vogel sob influência da adubação fosfatada e da calagem.

\section{Material e métodos}

O estudo foi conduzido entre outubro de 2013 e fevereiro de 2014, no Viveiro de Pesquisa do Departamento de Engenharia Florestal, pertencente à Universidade Federal de Viçosa (UFV), em Viçosa, Minas Gerais. Segundo a classificação de Köppen, o clima na região de Viçosa é do tipo $\mathrm{Cwb}$, mesotérmico com verões quentes e chuvosos, e invernos frios e secos. A temperatura e a precipitação pluviométrica média anual são de $19,4{ }^{\circ} \mathrm{C}$ e $1.221 \mathrm{~mm}$, respectivamente (DNMET 1992).

O substrato utilizado foi um Latossolo Vermelho-Amarelo distrófico, textura argilosa, retirado de uma área pertencente à UFV, na camada de 20-50 cm de profundidade. Posteriormente, o solo foi peneirado (malha de $4 \mathrm{~mm}$ de diâmetro) e destinado ao enchimento dos vasos. Desse solo, foi coletada amostra para caracterização física (argila $=570 \mathrm{~g} \mathrm{~kg}^{-1}$, silte $=110 \mathrm{~g} \mathrm{~kg}^{-1}$, areia grossa $=190 \mathrm{~g} \mathrm{~kg}^{-1}$ e areia fina $\left.=130 \mathrm{~g} \mathrm{~kg}^{-1}\right)$ e química (Tabela 1$)$.

\section{Tabela 1. Características químicas da amostra do solo utilizado para a produção de mudas de Dipteryx alata.}

\begin{tabular}{|c|c|c|c|c|c|c|c|c|c|c|c|c|}
\hline $\mathrm{pH}$ & $\mathrm{P}$ & $\mathrm{K}$ & $\mathrm{Al}^{3+}$ & $\mathrm{Ca}^{2+}$ & $\mathrm{Mg}^{2+}$ & $\mathrm{H}+\mathrm{Al}$ & SB & $\operatorname{CTC}(t)$ & CTC(T) & V & $\mathrm{m}$ & $\mathrm{MO}$ \\
\hline $\mathrm{H}_{2} \mathrm{O}$ & & & & & & & & & & & & $\mathrm{kg}^{-1}$ \\
\hline 4,79 & 0,70 & 6,00 & 0,92 & 0,11 & 0,01 & 3,93 & 0,14 & 1,06 & 4,04 & 3,5 & 86,80 & 1,66 \\
\hline
\end{tabular}

pH em água - Relação 1: 2,5; P e K - Extrator Mehlich 1; $\mathrm{Ca}^{2+}, \mathrm{Mg}^{2+}$ e $\mathrm{Al}^{\beta^{+}}$- Extrator: $\mathrm{KCl} 1 \mathrm{~mol} \mathrm{~L}{ }^{-1} ; \mathrm{H}+\mathrm{Al}-$ Extrator CaOAc 0,5 mol L-1, pH 7,0; $S B=$ Soma de bases; $C T C(t)=$ Capacidade de troca catiônica efetiva; $C T C(T)=$ Capacidade de troca catiônica, $p H$ 7,0; $V$ = Saturação por bases; $m$ = Saturação por alumínio; Matéria orgânica $(\mathrm{MO})=$ C. org. $x$ 1,724 - Método Walkley-Black.

Os tratamentos foram representados por um fatorial de sete níveis de $\mathrm{P}(0,80,160,240$, $320,400,480 \mathrm{mg} \mathrm{dm}^{-3}$ ) e por quatro níveis de saturação por bases do substrato (3,5 (original), 20, 40 e $60 \%$ ), sendo dispostos no delineamento em blocos ao acaso, com cinco repetições. A parcela experimental foi constituída por um vaso de polietileno rígido $\left(1,8 \mathrm{dm}^{3}\right)$. 
O solo recebeu quatro níveis de calagem, de acordo com o método da saturação por bases, ou seja, $3,5 \%$ (saturação por bases em condições naturais), e elevação da saturação por bases para 20, 40, 60\%, de acordo com a equação 1 .

$N C=[(V 2-V 1) \times T] \div 100$

Em que:

$\mathrm{NC}=$ necessidade de calagem $\left(\mathrm{t} \mathrm{ha}^{-1}\right)$;

$\mathrm{V} 2$ = porcentagem de saturação por bases desejadas;

V1 = porcentagem de saturação por bases do solo, conforme análise;

$\mathrm{CTC}(\mathrm{T})=$ Capacidade de troca catiônica a $\mathrm{pH}$ 7,0.

O corretivo consistiu de uma mistura de $\mathrm{CaCO}_{3}$ e $\mathrm{MgCO}_{3}$, na relação estequiométrica de 4:1. Após a aplicação do corretivo, o solo foi incubado durante 30 dias, com o teor de umidade mantido próximo à capacidade de campo, incluindo a porção que não recebeu calcário.

Antes da semeadura, a parte carnosa dos frutos foi retirada com auxílio de uma peneira, após os mesmos permanecerem por 48 horas em água. Foram semeados três frutos em cada vaso e realizado o raleio conforme necessário, deixando apenas uma muda por vaso.

A fonte de $\mathrm{P}$ utilizada foi o fosfato de sódio monobásico-monohidratado $\left(\mathrm{NaH}_{2} \mathrm{PO}_{4}\right.$. $\mathrm{H}_{2} \mathrm{O}$ ) aplicado por solução antes da semeadura. A adubação básica foi aplicada por solução após 30 dias do início da germinação das sementes e consistiu de $100 \mathrm{mg} \mathrm{dm}^{-3} \mathrm{de} \mathrm{N}, 100 \mathrm{mg} \mathrm{dm}^{-3}$ de $\mathrm{K}$ e $40 \mathrm{mg} \mathrm{dm}^{-3}$ de S, pelo emprego de $\mathrm{NH}_{4} \mathrm{NO}_{3}, \mathrm{KCl}_{\text {e }} \mathrm{K}_{2} \mathrm{SO}_{4}$ respectivamente, conforme sugerido por Passos (1994). Foi realizada uma adubação de cobertura de $50 \mathrm{mg} \mathrm{dm}^{-3}$ de $\mathrm{Ne}$ $50 \mathrm{mg} \mathrm{dm}^{-3}$ de $\mathrm{K}$ após intervalo de 40 dias. Juntamente a primeira adubação foi aplicada uma solução de micronutrientes nas seguintes doses: $0,81 \mathrm{mg} \mathrm{dm}^{-3}$ de $\mathrm{B}\left(\mathrm{H}_{3} \mathrm{BO}_{3}\right), 1,33 \mathrm{mg} \mathrm{dm}^{-3} \mathrm{de}$ $\mathrm{Cu}\left(\mathrm{CuSO}_{4} \cdot 5 \mathrm{H}_{2} \mathrm{O}\right), 3,66 \mathrm{mg} \mathrm{dm}{ }^{-3}$ de $\mathrm{Mn}\left(\mathrm{MnCl}_{2} \cdot \mathrm{H}_{2} \mathrm{O}\right), 4,00 \mathrm{mg} \mathrm{dm}{ }^{-3}$ de $\mathrm{Zn}\left(\mathrm{ZnSO}_{4} .7 \mathrm{H}_{2} \mathrm{O}\right)$, e $0,15 \mathrm{mg} \mathrm{dm}^{-3}$ de $\mathrm{Mo}\left(\left(\mathrm{NH}_{4}\right)_{6} \mathrm{Mo}_{7} \mathrm{O}_{24} \cdot 4 \mathrm{H}_{2} \mathrm{O}\right)$, de acordo com Alvarez V. et al. (2006).

Durante o período experimental, a umidade do solo foi monitorada diariamente, sendo feita a irrigação conforme a necessidade. Aos 120 dias após a semeadura, foram feitas medições da altura e diâmetro do coleto de todas as plantas utilizando régua graduada em centímetros e paquímetro digital com precisão de $0,01 \mathrm{~mm}$, respectivamente. As plantas foram separadas em raiz e parte aérea, lavadas e secadads em estufa com circulação forçada de ar, a uma temperatura próxima a $70{ }^{\circ} \mathrm{C}$, por 72 horas. Posteriormente, as partes constituintes das plantas foram pesadas em balança analítica com precisão de 0,01 g. Com os dados de altura $(\mathrm{H})$, diâmetro do coleto (DC), massa de matéria seca da parte aérea (MSPA), de raiz (MSRA) e total (MST), foi calculada a relação MSPA/MSRA e o Índice de Qualidade de Dickson (IQD) (Equação 2).

$I Q D=M S T \div[(H \div D C)+(M S P A \div M S R A)]$

Os resultados foram avaliados por meio de análise de variância e de regressão. Foram ajustadas equações de regressão com todas as observações e os modelos foram escolhidos pelo realismo biológico, significância da regressão e dos seus parâmetros. Também foi calculado o coeficiente de correlação de Pearson para avaliar a correlação entre as variáveis dependentes.

\section{Resultados e discussão}


A interação entre a adubação fosfatada e a saturação por bases apresentou efeito significativo $(\mathrm{p}<0,05)$ para a maioria das características, exceto para o DC e a MSPA/MSRA, sendo que o DC não respondeu a nenhum dos fatores estudados (Tabela 2).

Tabela 2. Resumo da análise de variância das características morfológicas e suas relações para mudas de Dipteryx alata, aos 120 dias após a semeadura, em resposta ao fósforo $(P)$ e saturação por bases do substrato (V).

\begin{tabular}{ccccccccc}
\hline \multirow{2}{*}{ FV } & \multirow{2}{*}{$\mathbf{T L}$} & $\mathbf{H}$ & DC & MSPA & MSRA & MST & MSPA/MSRA & IQD \\
\hline Bloco & 4 & 0,4138 & 0,0810 & 0,4580 & 0,6536 & 0,4770 & 0,6474 & 0,1850 \\
V & 3 & 0,0990 & 0,3773 & 0,0326 & 0,0029 & 0,0170 & 0,0072 & 0,0773 \\
P & 6 & 0,9128 & 0,2339 & 0,0607 & 0,0048 & 0,0188 & 0,0090 & 0,0083 \\
PxV & 18 & 0,0155 & 0,4225 & 0,0048 & 0,0098 & 0,0022 & 0,7813 & 0,0057 \\
Resíduo & 108 & & & & & & & \\
CV \% & & 15,38 & 12,68 & 24,82 & 34,31 & 26,11 & 32,42 & 31,35 \\
\hline
\end{tabular}

H-altura da parte aérea; DC - diâmetro do coleto; MSPA - massa de matéria seca da parte aérea; MSRA - massa de matéria seca da raiz; MST - massa de matéria seca total; MSPA/MSRA - relação entre massa de matéria seca da parte aérea e massa de matéria seca da raiz; IQD - índice de qualidade de Dickson.

Para todas as características avaliadas, exceto IQD, os valores máximos foram obtidos na saturação por bases de $20 \%$ no tratamento sem fósforo. Para a relação MSPA/MSRA em função de $\mathrm{V}$, o valor máximo foi obtido na saturação de $60 \%$ (Tabela 3 ).

Tabela 3. Equações de regressão para as características morfológicas e suas relações para mudas de Dipteryx alata, aos 120 dias após a semeadura, em resposta ao fósforo $(P)$ e saturação por bases do substrato (V).

\begin{tabular}{|c|c|c|c|c|}
\hline Variável dependente & $\mathrm{V}(\%)$ & Regressão & $\mathbf{R}^{2}$ & p-valor \\
\hline \multirow[t]{4}{*}{$\mathrm{H}(\mathrm{cm})$} & $\begin{array}{l}3,5 \\
20 \\
40\end{array}$ & $\begin{array}{c}\hat{Y}=\bar{Y}=18,16 \\
\hat{Y}=21,5685-0,03128^{*} P+0,00005488^{*} P^{2} \\
\hat{Y}=\bar{Y}=17,03\end{array}$ & 0,19 & 0,0309 \\
\hline & 60 & $\hat{Y}=15,7044+0,005525 \mathrm{P}$ & 0,13 & 0,0368 \\
\hline & 3,5 & $\hat{Y}=3,1936-0,001389^{*} P$ & 0,12 & 0,0382 \\
\hline & 20 & $\dot{\hat{Y}}=3,7025-0,001928^{*} \mathrm{P}$ & 0,14 & 0,0293 \\
\hline \multirow[t]{3}{*}{ MSPA (g) } & 40 & $\hat{Y}=\bar{Y}=3,09$ & & \\
\hline & $\begin{array}{l}60 \\
3,5\end{array}$ & $\begin{array}{c}\hat{Y}=2,09283+0,008481^{*} \mathrm{P}-0,00001644^{*} \mathrm{P}^{2} \\
\hat{\mathrm{Y}}=\overline{\mathrm{Y}}=3,17\end{array}$ & 0,22 & 0,0177 \\
\hline & 20 & $\hat{Y}=3,5715-0,002779^{*} P$ & 0,20 & 0,0064 \\
\hline \multirow[t]{2}{*}{ MSRA (g) } & 40 & $\hat{Y}=3,4373-0,00297^{*} P$ & 0,20 & 0,0072 \\
\hline & $\begin{array}{l}60 \\
3,5\end{array}$ & $\begin{array}{l}\hat{Y}=\bar{Y}=2,31 \\
\hat{Y}=\bar{Y}=6.03\end{array}$ & & \\
\hline \multirow{3}{*}{$\operatorname{MST}(g)$} & 20 & $\hat{Y}=7,2740-0,004707^{*} P$ & 0,19 & 0,0079 \\
\hline & 40 & $\hat{Y}=6,9454-0,004698^{*} P$ & 0,17 & 0,0128 \\
\hline & $\begin{array}{l}60 \\
3,5 \\
20\end{array}$ & $\begin{array}{c}\hat{Y}=4,1118+0,01553^{*} P-0,00003317^{*} P^{2} \\
\hat{Y}=\bar{Y}=1,49 \\
\hat{Y}=\bar{Y}=1,43\end{array}$ & 0,18 & 0,0415 \\
\hline IQD & 40 & $\hat{Y}=1,7197-0,001564^{*} P$ & 0,27 & 0,0013 \\
\hline $\begin{array}{l}\text { MSPA/MSRA }=f(V) \\
\text { MSPA/MSRA }=f(P)\end{array}$ & 60 & $\begin{array}{c}\hat{Y}=\bar{Y}=1,23 \\
\hat{Y}=1,02418+0,005277^{*} V \\
\hat{Y}=\bar{Y}=1,18\end{array}$ & 0,08 & 0,0009 \\
\hline
\end{tabular}

*Significativo a $5 \%$ de probabilidade pelo teste $t$-Student. $H$ - altura da parte aérea; DC - diâmetro do coleto; MSPA - massa de matéria seca da parte aérea; MSRA - massa de matéria seca da raiz; MST - massa de matéria seca total; MSPA/MSRA - relação entre massa de matéria seca da parte aérea e massa de matéria seca da raiz; IQD índice de qualidade de Dickson.

FREITAS, E.C.S. ET AL. 
Apesar da maioria das respostas em função das doses de $\mathrm{P}$, dentro dos níveis de $\mathrm{V}$, terem sido negativas, ressalta-se que os coeficientes lineares das equações foram inferiores a 0,04, e os coeficientes quadráticos menores que 0,0001 . Nesse sentido, mesmo que a resposta tenha sido negativa, a diferença dos valores obtidos para as variáveis dependentes entre as doses mínima e máxima de $\mathrm{P}$ foi pequena. Essa baixa resposta aos tratamentos foi observada durante o experimento, uma vez que as mudas não apresentavam, visualmente, diferença expressiva de crescimento (Figura 1).

\section{Figura 1. Mudas de Dipteryx alata aos 120 dias após a semeadura.}

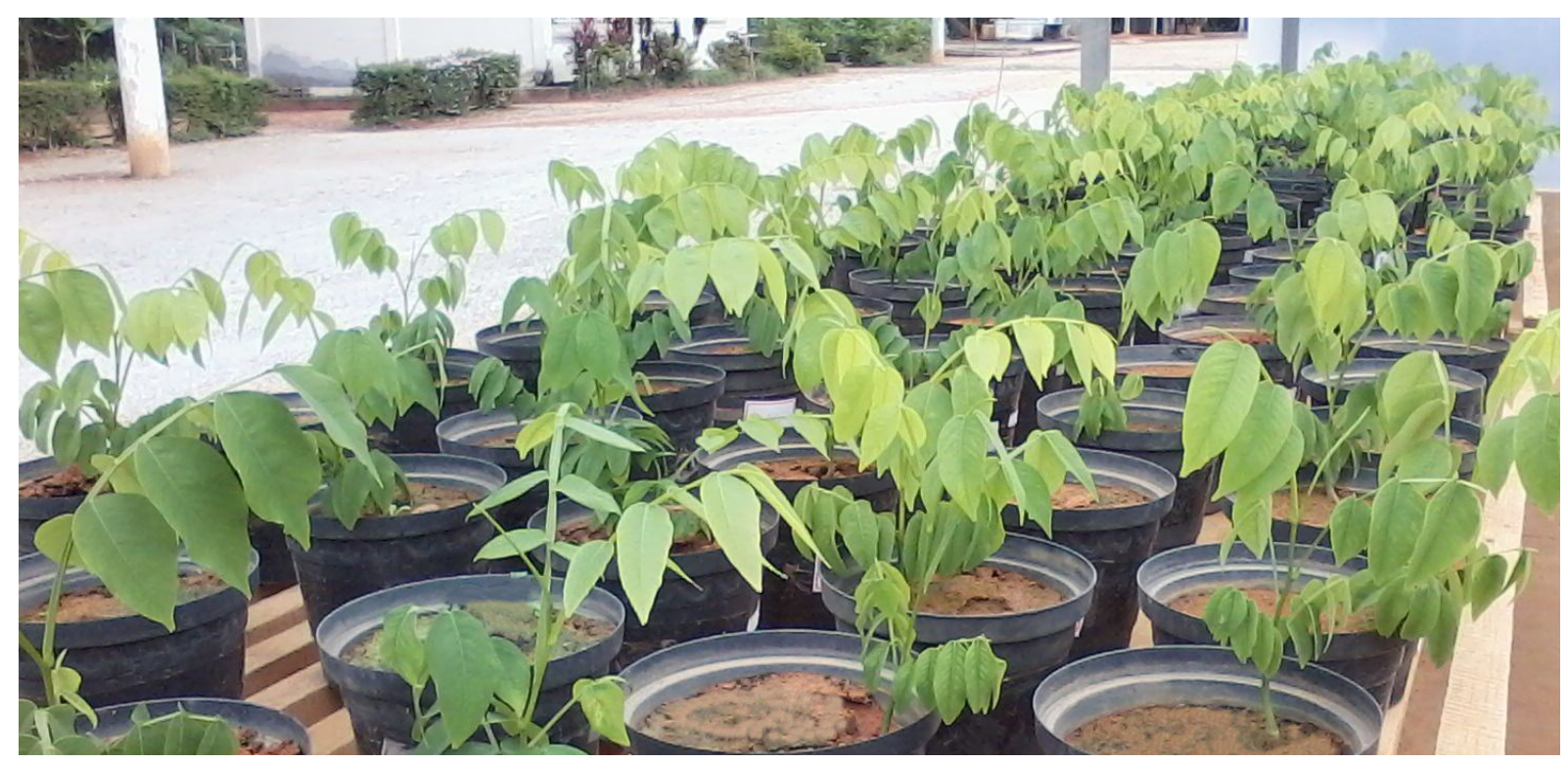

Fonte: Freitas et al. (2014)

As espécies pioneiras, de modo geral, são mais exigentes nutricionalmente, mostrando-se mais responsivas à fertilização, ao passo que, com o avanço do grupo sucessional, o estímulo ao crescimento proporcionado pela adubação é menos pronunciado ou inexistente, tendência, em parte, atribuída ao crescimento mais lento (FURTINI NETO et al., 2005; SANTOS et al.,2008). Contudo, para mudas de pau-de-balsa (Ochroma lagopus Sw.), espécie pioneira, Tucci et al. (2010) não observaram efeitos significativos para absorção de fósforo. Esses resultados evidenciam que a demanda de fósforo pelas espécies está associada a diversos fatores, não sendo recomendado generalizar considerando apenas um deles.

De acordo com Santos et al. (2008), maiores respostas ao fornecimento de fósforo são esperadas em espécies de sementes pequenas e com baixos teores desse nutriente, sistema radicular pouco desenvolvido, maior capacidade micotrófica, maior taxa de crescimento e na fase inicial de desenvolvimento. Para mudas de Caryocar brasiliense (pequi), Carlos et al. (2014) observaram que a biomassa seca total não foi afetada pelas omissões dos nutrientes. Esses autores ressaltaram que a baixa exigência nutricional do pequi, baixos teores de nutrientes na biomassa seca da parte aérea, durante o processo de formação de mudas pode ser devido à adaptação a solos pobres e ácidos ou às reservas contidas nas sementes, suficientes para a fase de formação das mudas.

Resultado semelhante foi observado para o jatobá-do-cerrado (Hymenaea stigonocarpa), em que a adubação fosfatada proporcionou pouco ganho no crescimento das mudas (ALVES et al., 
2015). Segundo os autores, essa resposta é justificada pelo crescimento inicial lento da espécie (clímax) e por ser adaptada a solos com baixa fertilidade, como os do Cerrado.

As mesmas considerações em relação ao grupo sucessional são feitas para calagem, em que o esperado é que espécies pioneiras sejam mais responsivas à correção da acidez, e com o avanço do grupo sucessional (espécies secundárias e clímax), o estímulo ao crescimento proporcionado pela calagem seja menos pronunciado (FURTINI NETO et al., 1999), como o observado no presente estudo, em que os valores máximos para crescimento foram obtidos na saturação por bases de $20 \%$.

Todavia, diferentes respostas e independentes do grupo sucessional são obtidas por diversos autores. A calagem teve influência positiva na produção de mudas de Machaerium nictitans (SOUZA et al., 2008), Senna multijuga, Stenolobium stans, Anadenanthera falcata e Cedrela fissilis (FURTINI NETO et al., 1999). Ao passo que, muitas espécies não responderam à aplicação de corretivos ao substrato, como observado para Anadenanthera colubrina (GOMES et al., 2004); Tabebuia impetiginosa (CRUZ et al., 2004); Astronium fraxinifolium, Guazuma ulmifolia, Anadenanthera macrocarpa e Inga edulis (SILVA et al., 2011a).

A baixa resposta à calagem pode ser explicada pela adaptação do baru a solos ácidos e à sua exigência nutricional na fase inicial de crescimento. A resposta à prática de calagem depende das características de cada espécie cultivada e sua tolerância à acidez, sendo que espécies mais tolerantes possuem mecanismos para reduzir a absorção de $\mathrm{Al}$, aumentando o $\mathrm{pH}$ da rizosfera ou excluindo-o do tecido (VALE et al., 1996).

Gonçalves et al. (2005) estabeleceram um intervalo de altura entre 20 a 35

$\mathrm{cm}$ e diâmetro do coleto entre 5 e $10 \mathrm{~mm}$ para mudas com boa qualidade. A altura máxima da parte aérea $(21,57 \mathrm{~cm})$, em $\mathrm{V}=20 \%$ e $\mathrm{P}=0 \mathrm{mg} \mathrm{dm}$, , e o diâmetro do coleto médio $(5,77 \mathrm{~mm})$, obtidos no presente estudo, enquadram-se nesse intervalo. Entretanto, ressalta-se que a massa de matéria seca das mudas, apesar de ser aferida por método destrutivo, e, portanto, mais difícil de ser utilizada no viveiro, exprime melhor relação com o vigor das mudas, pois é o resultado da capacidade fotossintética (CRUZ et al., 2011). No presente estudo, a máxima MST foi obtida no mesmo nível de $\mathrm{V}$ e $\mathrm{P}$ que a altura máxima.

Segundo Gomes \& Paiva (2012), a melhor relação entre a massa de matéria seca da parte aérea e a respectiva massa de matéria seca de raiz ficou estabelecida como 2. Entretanto, os resultados para essa relação variam de acordo com a espécie e o ambiente em que a mesma foi adaptada, disponibilidade hídrica e de nutrientes, diferindo o investimento em produção de parte aérea em relação ao sistema radicular. As plantas do cerrado, normalmente, apresentam sistema radicular mais desenvolvido que a parte aérea, como forma de adaptação aos solos ácidos e pobres em nutrientes (DURIGAN et al., 2011). Moreira \& Klink (2000) relataram que plantas do Cerrado investem predominantemente em sistema radicular nos estágios iniciais de desenvolvimento (5 - 7 meses), apresentando relação raiz/parte aérea entre 1 e 9 , sendo o maior investimento em sistema radicular um mecanismo para as plantas suportarem a estação seca e rebrotarem após o fogo, condições típicas desse bioma.

Para as mudas de baru, foi observado sistema radicular bem desenvolvido, com valores semelhantes de biomassa de raiz e parte aérea, resultando numa relação MSPA/MSRA igual a 1,0, corroborando com resultados de outros estudos com espécies do Cerrado. Em mudas de Brosimum gaudichaudii (mama-cadela), Palhares \& Silveira (2007) também observaram maior investimento no desenvolvimento da raiz com a manutenção de um mínimo de parte aérea, 
atingindo cerca de $50 \mathrm{~cm}$ de profundidade da raiz em menos de 10 meses. $O$ mesmo foi observado por Sano et al. (1995), que avaliaram o crescimento de mudas de Eugenia dysenterica (cagaita) em dois ambientes, a pleno sol e sombra. Para o ambiente a pleno sol, a relação entre massa de matéria seca da parte aérea e raiz foi igual a 1,0 aos 35 e 70 dias, e aos 105 e 140 dias a relação média foi de 0,55. Valores de MSPA/MSRA menores ou igual a 1,0 também foram observados para mudas de Hancornia speciosa (mangabeira) produzidas em diferentes substratos (SILVA et al.,2011b) e para Himenaea stigonocarpa (jatobá-do-cerrado) em diferentes ambientes e substratos (COSTA et al., 2010).

A MSPA/MSRA máxima $(1,34)$ foi obtida no $V$ máximo estudado, de $60 \%$. Isso pode ser justificado pela maior disponibilidade de fósforo com a maior saturação por bases do substrato e, consequentemente, menor investimento em sistema radicular. Em condições de baixa disponibilidade de fósforo a planta destina maior potencial de crescimento para o sistema radicular (SOARES et al., 2007).

Apesar das características analisadas estarem relacionadas positivamente com a sobrevivência e crescimento das mudas no campo, como relatado por alguns autores, elas podem responder diferentemente aos tratamentos de adubação e correção do solo. Através da resposta de uma característica a um determinado tratamento é possível inferir sobre a resposta de outra, quando essas possuem alta correlação. As correlações entre as características morfológicas, MSPA/ MSRA e IQD foram analisadas, sendo que aquelas envolvendo a matéria seca (da parte área, raiz ou total) ou IQD foram melhores (Figura 2). As correlações de $\mathrm{H}$ e $\mathrm{DC}$ foram maiores com a MSPA, entretanto para as outras variáveis, inclusive a MSPA/MSRA e IQD, as correlações foram maiores com a MSRA.

Figura 2. Coeficiente de correlação de Pearson entre as variáveis
dependentes.
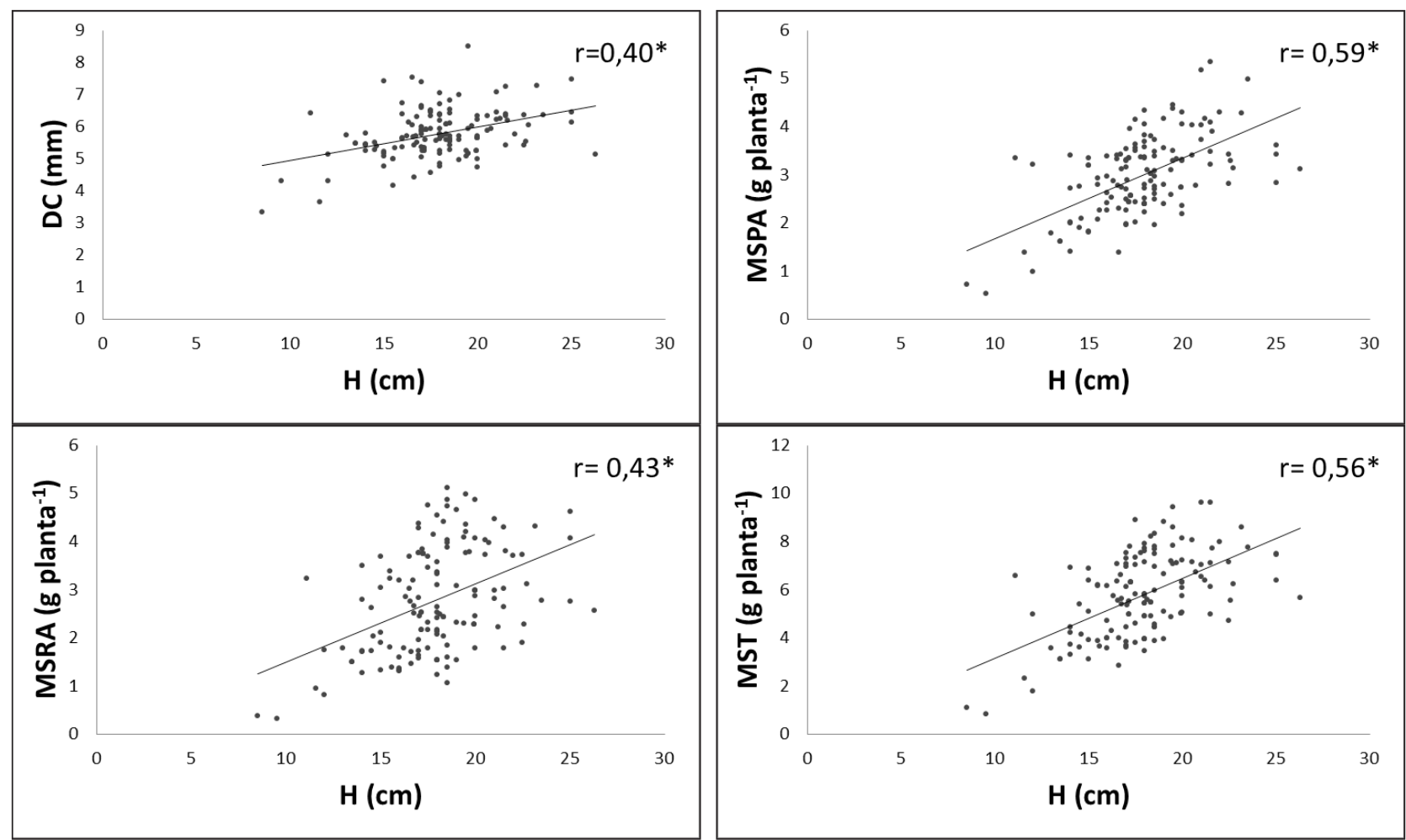

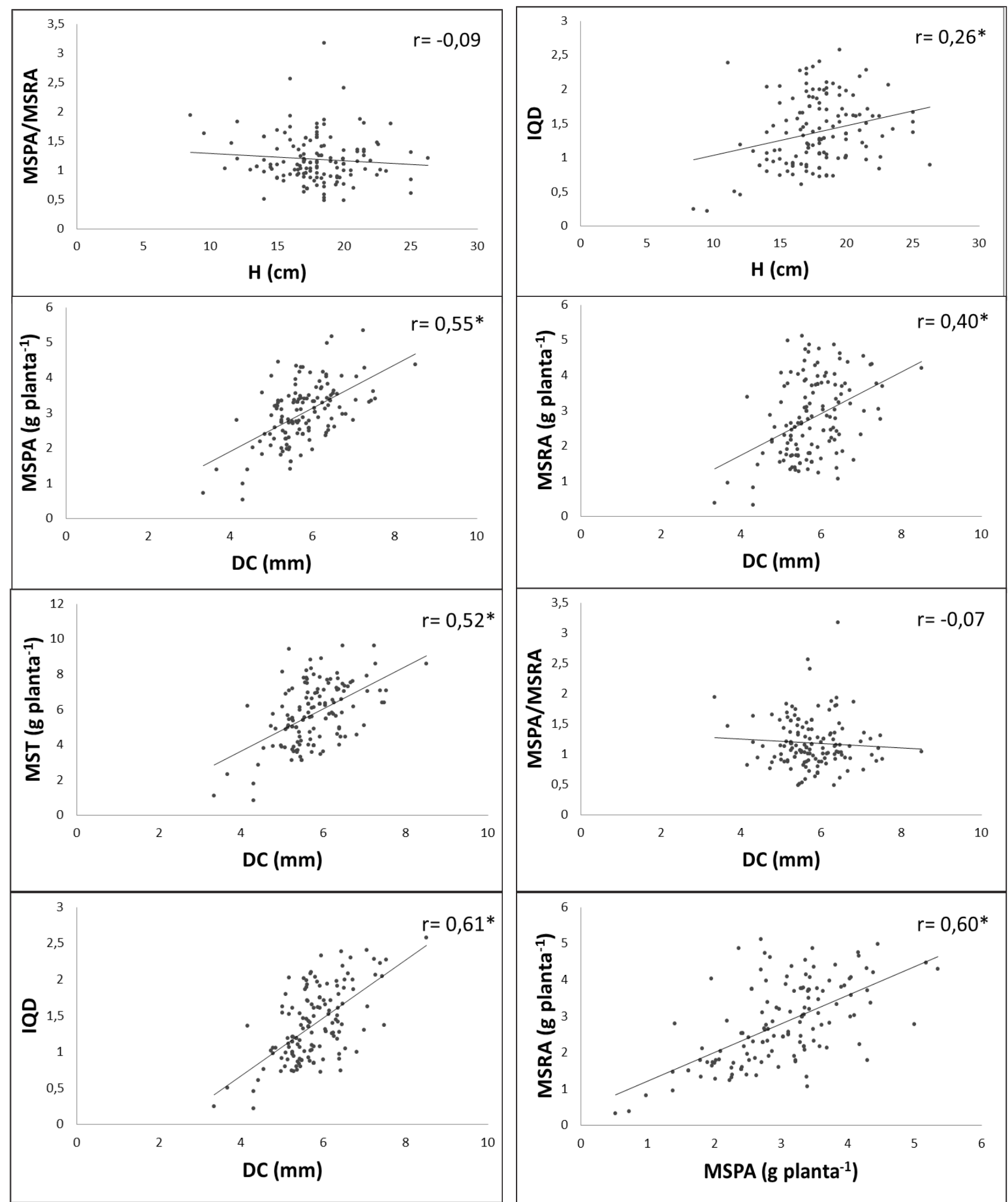


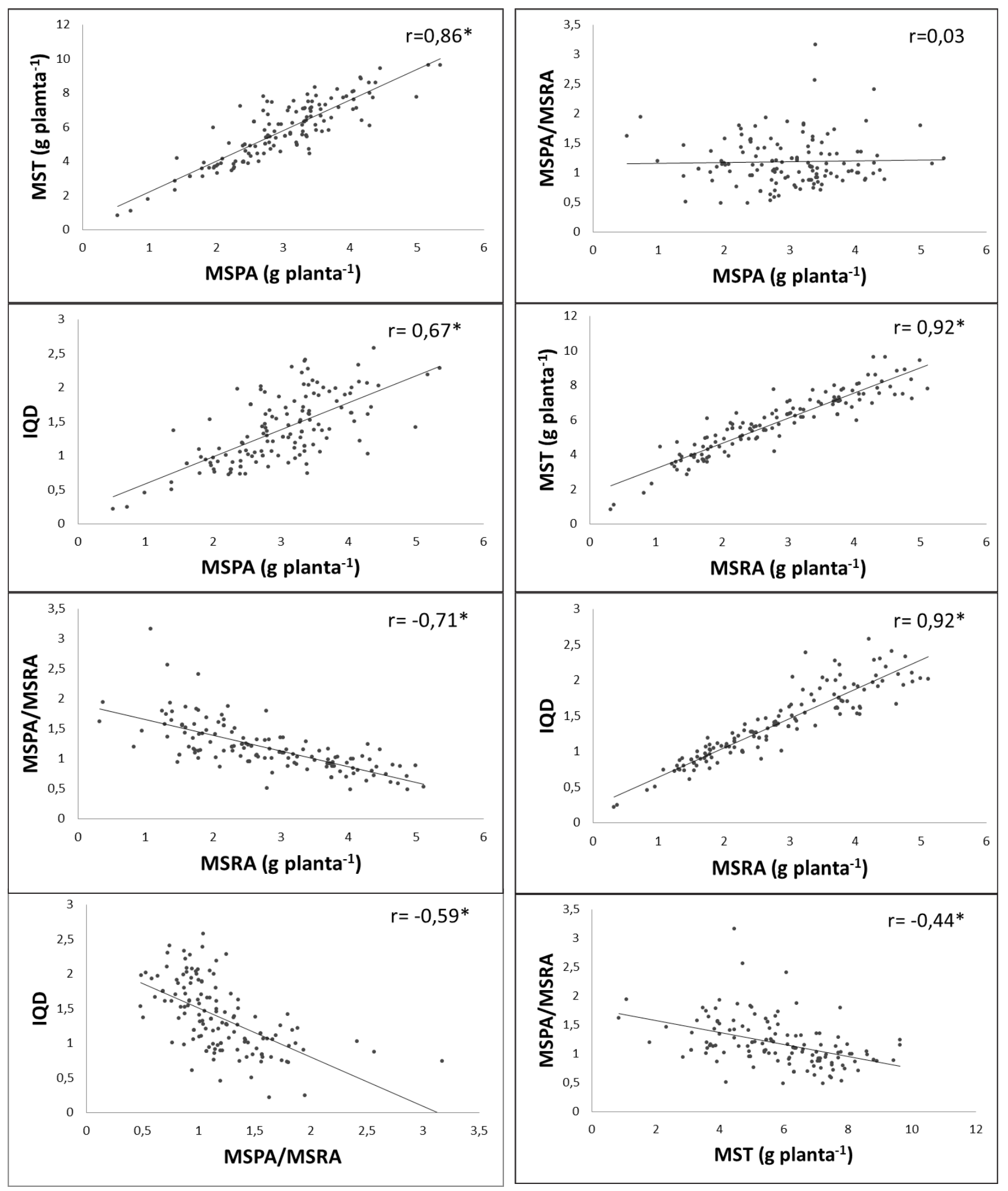




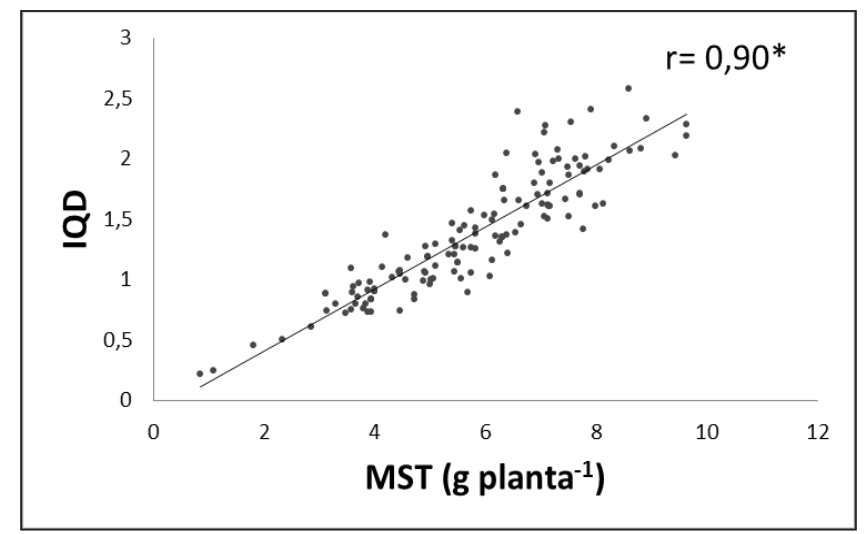

*Significativo a 5\% de probabilidade. $H$ - altura da parte aérea; DC - diâmetro do coleto; MSPA - massa de matéria seca da parte aérea; MSRA - massa de matéria seca da raiz; MST - massa de matéria seca total; MSPAMSRA relação entre massa de matéria seca da parte aérea e massa de matéria seca da raiz; IQD - índice de qualidade de Dickson.

Fonte: Freitas et al. (2014).

Ambas MSPA e MSRA apresentaram alta correlação com a MST, como era esperado, embora a $r_{\text {MSRA,MST }}$ tenha sido maior que a $r_{\text {MSPA,MST. }}$ Assim, a influência negativa da adubação fosfatada na produção do sistema radicular explica a resposta negativa desse nutriente na massa de matéria seca total. Em 1974, Poggiani observou que a adubação fosfatada inibiu o alongamento da raiz de duas espécies do Cerrado, Stryphnodendron adstringens (barbatimão) e Dimorphandra mollis (faveiro).

A MST é a característica que melhor reflete a produção (GONÇALVES et al., 2008) e apresentou as maiores correlações com as outras variáveis dependentes, inclusive com o IQD. Esse índice é muito utilizado para inferir a respeito da qualidade das mudas, pois, no seu cálculo são considerados a robustez e o equilíbrio da distribuição da biomassa na muda, ponderando os resultados de várias características importantes empregadas para avaliação da qualidade (FONSECA et al., 2002). Portanto, ambos, MST e IQD, podem ser empregados para avaliar o crescimento e a qualidade das mudas em função dos tratamentos aplicados.

\section{Conclusões}

O crescimento das mudas de baru foi pouco influenciado pela saturação por bases do substrato e adubação fosfatada nas condições estudadas, sendo recomendada a elevação da saturação por bases para 20\%, sem necessidade de aplicar fósforo.

\section{Referências}

ALVAREZ V., V. H; DIAS, L.E.; LEITE, P. B.; SOUZA R. B.; RIBEIRO JUNIOR, E. $\mathrm{S}$. Poda de raízes e adubação para crescimento do cafeeiro cultivado em colunas de solo. Revista Brasileira de Ciência do Solo, Viçosa, v.30, n.1, p. 111-119, 2006. 
ALVES, J. D. N.; SOUZA, F. C. A.; OLIVEIRA, M. L.; OLIVEIRA, M. C. M. A.; OKUMURA, R. S. Fontes de fósforo no crescimento inicial de mudas de jatobá-docerrado (Hymenaea stigonocarpa Mart.). Nucleus, Ituverava, v.12, n.2, p.299-308, 2015.

ANDRADE, A.M.; CARVALHO, C.J.Produção de celulose e de papel Kraft da madeira de baru (Dipteryx alata Vog.). Floresta e Ambiente, Seropédica, v.3, n.2, p. 28-35, 1996.

AVIDOS, M.F.D.; FERREIRA, R.T. Frutos dos cerrados: preservação gera muitos frutos. Biotecnologia Ciência e Desenvolvimento, Brasília, v.3, n.15, p.36-41, 2000.

CARLOS, L.; VENTURIN, N.; MACEDO, R.L.G.; HIGASHIKAWA, E.M.; GARCIA, M.B.; FARIAS, E.S. Crescimento e nutrição mineral de mudas de pequi sob efeito da omissão de nutrientes. Ciência Florestal, Santa Maria, v. 24, n. 1, p. 13-21, 2014.

CARNEIRO, J. G. A. Produção e controle de qualidade de mudas florestais. Curitiba: UFPR/ FUPEF/UENF, 1995. 451 p.

CARVALHO, P.E.R. Espécies florestais brasileiras: recomendações silviculturais, potencialidades e uso da madeira. Brasília: EMBRAPA - CNPF/SPI, 1994. 640p.

COSTA, E.; LEAL, P. A. M.; REGO, N. H.; BENATTI, J. Desenvolvimento inicial de mudas de jatobazeiro do cerrado em Aquidauana-MS. Revista Brasileira de Fruticultura, Jaboticabal, v. 33, n. 1, p. 215-226, 2011.

CRUZ, C.A.F.; PAIVA, H.N; GOMES, K.C.O.; GUERRERO, C.R.A. Efeito de diferentes níveis de saturação por bases no desenvolvimento e qualidade de mudas de ipê-roxo (Tabebuia impetiginosa (Mart.) Standley). Scientia Forestalis, Piracicaba, n.66, p.100-107, dez. 2004.

CRUZ, C.A.F; PAIVA, H.N.; CUNHA, A.C.M.C.M.; NEVES,J.C.L. Crescimento e qualidade de mudas de Fedegoso cultivadas em latossolo vermelho-amarelo em resposta a macronutrientes. Scientia Forestalis, Piracicaba, v. 39, n. 89, p.21-03, mar. 2011.

DNMET - DEPARTAMENTO NACIONAL DE METEOROLOGIA. Normais climatológicas (1961-1990). Brasília: SPI/EMBRAPA, 1992.84 p.

DURIGAN, G.; MELO, A.C.G.; MAX, J.C.M.; VILAS BOAS, O.; CONTIERI, W.A.; RAMOS, V.S.. Manual para recuperação da vegetação de cerrado. 3.ed. São Paulo: SMA, 2011.19 p.

FONSECA, E. P.; VALÉRI, S. V.; MIGLIORANZA, E.; FONSECA, N. A. N.; COUTO, L. Padrão de qualidade de mudas de Trema micrantha (L.) Blume, produzidas sob diferentes períodos de sombreamento. Revista Árvore, Viçosa, v.26, n.4, p.515-523, 2002. 
FURTINI NETO,A.E.; RESENDE,A.V.; VALE, F.R.; FAQUIN,V.; FERNANDES, L. A. Acidez do solo, crescimento e nutrição mineral de algumas espécies arbóreas, na fase de muda. Cerne, Lavras, v.5, n.2, p.01-12, 1999.

FURTINI NETO, A.E.; SIQUEIRA, J.O.; CURI, N.; MOREIRA, F.M.S. Fertilização em reflorestamentos com espécies nativas. In: GONÇALVES, J. L. M.; BENEDETI, V. (Eds.). Nutrição e fertilização florestal. Piracicaba: IPEF, 2005. p. 351-384.

GOMES, K. C. O.; PAIVA, H. N.; NEVES, J. C.L.; BARROS, N.F.; SILVA., S.R. Influência da saturação por bases e do fósforo no crescimento de mudas de angico-branco. Revista Árvore, Viçosa, v.28, n.6, p.785-792, 2004.

GOMES, J.M.; PAIVA, H.N. Viveiros florestais: propagação sexuada. Viçosa, MG: Editora UFV, 2012.116p.

GONÇALVES,J.L.M.; SANTARELI, E. G.; MORAES NETO, S.P.; MANARA, M. P.Produção de mudas de espécies nativas: substrato, nutrição, sombreamento e fertilização. In: GONÇALVES, J. L. M.; BENEDETI, V. (Eds.). Nutrição e fertilização florestal. Piracicaba: IPEF, 2005. p. 309-350.

GONÇALVES, E.O.; PAIVA, H.N.; NEVES, J.C.L.; GOMES, J.M. Crescimento de mudas de angico-vermelho (Anadenanthera macrocarpa (Benth.) Brenan) sob diferentes doses de macronutrientes. Revista Árvore, Viçosa, v.32, n.6, p.1029-1040, 2008.

IBGE. Indicadores de Desenvolvimento Sustentável - IDS 2012. Disponível em: $<\mathrm{ftp}$ ///geoftp.ibge.gov.br/documentos/recursos_naturais/indicadores_desenvolvimento_ sustentavel/2012/ids2012.pdf > Acesso em: 11 jul. 2013.

KLINK, C.A.;MACHADO, R.B. A conservação do Cerrado brasileiro.Megadiversidade, Belo Horizonte, v.1, n.1, p.147-155, jul. 2005.

LORENZI,H.Árvores brasileiras: manual de identificação e cultivo de plantas arbóreas nativas do Brasil. 4.ed. Nova Odessa: Instituto Plantarum, 2002.368p.

MOREIRA, A.; KLINK, CA. Biomass allocation and growth of tree seedlings from two contrasting Brazilian savannas. Ecotropicos, Mérida, v. 13, n. 1, p. 43-51, 2000.

NOVAIS, R.F.; MELLO, J.W.V. Relação solo-planta. In: NOVAIS, R.F.; ALVAREZ V., V.H.; BARROS, N.F.; FONTES, R.L.F.; CANTARUTTI, R.B.; NEVES, J.C.L. Fertilidade do solo. Viçosa: Sociedade Brasileira de Ciência do Solo, 2007. p.133-204.

PALHARES, D.; SILVEIRA, C.E.S. Aspectos morfológicos de plantas jovens de Brosimum gaudichaudii produzidas em condições alternativas de cultivo. Revista Brasileira de Plantas Medicinais, Paulinia, v.9, n.1, p.93-96, 2007. 
PASSOS, M. A. A. efeito da calagem e de fósforo no crescimento inicial da algaroba (prosopis juliflora $(S W) D C$ ). 1994.57f. Tese (Doutorado em Fitotecnia) - Universidade Federal de Viçosa, Viçosa, MG.

POGGIANI, F. Efeito de alguns nutrientes sobre o crescimento inicial de duas espécies arbóreas do cerrado. IPEF, n.8, p.3-12, 1974.

SANO, S.M.; VIVALDI, L.J.; SPEHAR, C.R. Diversidade morfológica de frutos e sementes de baru (Dipteryx alata Vog.). Pesquisa Agropecuária Brasileira, Brasília, v. 34, n. 14, p. 513-518, abr. 1999.

SANO, S. M.; FONSECA, C. E. L.; RIBEIRO, J. F.; OGA, F. M.; LUIZ, A. J. B. Folhação, floração, frutificação e crescimento inicial da cagaiteira em Panaltina, DF. Pesquisa Agropecuária Brasileira, Brasília, v. 30, n. 1, p. 5-14, 1995.

SANO, E. E.; JESUS, E. T.; BEZERRA, H. S. Uso de um sistema de informações geográficas para quantificação de áreas remanescentes do Cerrado. Planaltina: Embrapa Cerrados, 2001. 4 p. (Comunicado Técnico, 62).

SANTOS,D.R.; GATIBONI, L.C.; KAMINSKI,J. Fatores que afetam a disponibilidade do fósforo e o manejo da adubação fosfatada em solos sob sistema plantio direto. Ciência Rural, Santa Maria, v.38, n.2, p.576-586, mar./abr. 2008.

SILVA, J.A.; SILVA, D.J. da; JUNQUEIRA, N.T.V.; ANDRADE, L.R.M. de. Frutas nativas dos cerrados. Brasília: EMBRAPA-CPAC/SPI, 1994. 166p.

SILVA, A.H.; PEREIRA,J. S.; RODRIGUES, S.C. Desenvolvimento inicial de espécies exóticas e nativas e necessidade de calagem em área degradada do Cerrado no triângulo mineiro (Minas Gerais, Brasil). Agronomía Colombiana, Bogotá, v.29, n.2, p. 287-292, 2011a.

SILVA, E.A.; OLIVEIRA, A.C.; MENDONÇA, V.; SOARES, F.M. Substratos na produção demudas de mangabeira em tubetes. Pesquisa Agropecuária Tropical, Goiânia, v. 41, n. 2, p. 279-285, 2011b.

SOARES, I.; LIMA, S.C.; CRISÓSTOMO, L.A. Crescimento e composição mineral de mudas de gravioleira em resposta a doses de fósforo. Revista Ciência Agronômica, Fortaleza, v.38, n.4, p.343-349, 2007.

SOUZA, P.H.; PAIVA, H. N.; NEVES, J.C.L.; GOMES, J.M.; MARQUES, L. S. Influência da saturação por bases do substrato no crescimento e qualidade de mudas de Machaerium nictitans (Vell.) Benth. Revista Árvore, Viçosa, v.32, n.2, p.193-201, 2008. 
TAKEMOTO, E.; OKADA, I. A.; GARBELOTTI, M. L.; TAVARES, M.; AUEDPIMENTEL, S. Composição química da semente e do óleo de baru (Dipteryx alata Vog.) nativo do Município de Pirenópolis, Estado de Goiás. Revista Instituto Adolfo Lutz, São Paulo, v.60, n.2, p. 113-117, 2001.

TUCCI, C.A.F.; LIMA, H. N.; GAMA, A.S.; COSTA, H.S.; SOUZA, P. A. Efeitos de doses crescentes de calcário em solo Latossolo Amarelo na produção de mudas de pau-de-balsa (Ochroma lagopus sw., Bombacaceae). Acta Amazonica, Manaus, v.40, n.3, p.543-548, 2010.

VALE, F. R.; FURTINI NETO, A.E.; RENÓ, N.B.; FERNANDES, L.A.; RESENDE, A. V. Crescimento radicular de espécies florestais em solo ácido. Pesquisa Agropecuária Brasileira, Brasília, v.31, n.9, p.609-616, set. 1996. 